\title{
Feeding Potential of Adult Menochilus sexmaculata and Coccinella septempunctata on Passionvine Mealybug, Planococcus minor Eggs and Nymphs
}

\section{Muhammad Ishaque Mastoi ${ }^{*}$, Ibtasam Riaz ${ }^{2}$, Syed Muneeb Haider ${ }^{2}$, Arfan Ahmed Gilal ${ }^{3}$, Anjum Shehzad $^{4}$, Ahmed Zia ${ }^{4}$ and Abdul Rauf Bhatti ${ }^{4}$}

${ }^{1}$ Plant Sciences Division, Pakistan Agricultural Research Council Islamabad, Pakistan; ${ }^{2}$ Department of Zoology, University of Gujrat, Sub-campus Sialkot, Pakistan; ${ }^{3}$ Department of Entomology, Faculty of Crop Protection, SAU, Tandojam, Pakistan; ${ }^{4}$ National Insect Museum, IPEP, NARC Islamabad, Pakistan.

Abstract | Passionvine mealybug, Planococcus minor has caused severe losses to many important crops and vegetables. However, many natural enemies, particularly predators have demonstrated key influence on its population regulation. Thus, this laboratory study was conducted to evaluate feeding potential of two coccinellid predators i.e., Menochilous sexmaculata and Coccinella septempunctata on eggs and nymphs of $P$. minor. Results confirmed that both species of coccinellid showed feeding potential against eggs and nymphs of $P$. minor. Comparatively, $M$. sexmaculata showed higher feeding than $C$. septempunctata on various immature stages of $M$. minor. Moreover, both the species showed relatively more preference on eggs of $P$. minor than nymphs. Therefore, both the species can be exploited in field conditions against $P$. minor to keep its populations below threshold level.

Received | April 21, 2019; Accepted | May 22, 2019; Published | August 15, 2019

*Correspondence | Muhammad Ishaque Mastoi, Plant Sciences Division, Pakistan Agricultural Research Council Islamabad, Pakistan; Email: ishaqnscri@yahoo.com

Citation | Mastoi, M.I., I. Riaz, S.M. Haider, A.A. Gilal, A. Shehzad, A. Zia and A.R. Bhatti. 2019. Feeding potential of adult Menochilus sexmaculata and Coccinella septempunctata on passionvine mealybug, Planococcus minor eggs and nymphs. Pakistan Journal of Agricultural Research, 32(3): 544-548.

DOI | http://dx.doi.org/10.17582/journal.pjar/2019/32.3.544.548

Keywords | Ladybird beetles, Predator, Passionvine mealybug

\section{Introduction}

$P$ lanococcus minor (Maskell) (Hemiptera: Pseudococcidae), commonly known as passionvine mealybug, is a polyphagous pest that can potentially damage many tropical and subtropical plants (CAB, 2003; Venette and Davis, 2004). Although, this species is widely distributed in many South-Asian countries, but, it has cause serious damages in India and Taiwan (Reddy et al., 1997; Tandon and Verghese, 1987; Ho et al., 2007). Planococcus minor is a highly polyphagous pest that attack more than 250 plant species from 80 families (Bastos et al., 2007). Cit- rus, banana, cocoa corn, coffee, mango, grape, potato, and soybean are some of the important hosts of this mealybug (Ben-Dov, 1994, Venette and Davis, 2004). Besides, it also possesses highly invasive characteristics; free spread along with shipping goods particularly fruits (Venette and Davis, 2004), comparatively short life cycle (Martinez and Suris, 1998) and a high reproductive potential (Maity et al., 1998).

Mealybug infestation may occur within vegetative shoots or apexes and can be extremely difficult to detect. Basically, P. minor is phloem feeder that cause stunting growth of the plants along with defoliation 
that eventually cause considerable losses to yield of crops. Indirectly, this pest cause damage by developing sooty mold on the infested parts on their honey dew secretions and as a vector of plant viruses such as swollen shoot virus of cacao, Theobroma cacao L. (Cox, 1989). Moreover, ability of mealybugs to forms dense colonies, particularly within the shoots and apex, often makes chemical control of mealybugs quite difficult. Although,application of newinsecticides has improved the control strategies, but, due to their polyphagous nature, they can move from one host to another to make the chemical control less effective (Williams and Granara de Willink, 1992; Francis et al., 2012).

Typically, mealybugs in their countries of origin are not pest problems because naturally occurring parasitoids and predators in the locality keep their numbers in check. The most serious outbreak occurs when mealybugs are accidently introduced to new countries without their natural enemies. The introduction of pests via infested plant material has unfortunately become fairly common (Williams and Granara de Willink, 1992; Francis et al., 2012).

Ladybird beetles of coccinellidae family are worldwide effective predators of many noxious insect pests such as aphids, mealybugs, leafhoppers, lepidopterous eggs, borers, scale insects, white flies and mites during their various developing stages (Irshad, 2001). Around the world, more than 3,500 coccinellid species have been reported, whereas, around 75 species recorded in Pakistan (Mustafa et al., 1996; Irshad, 2001). Thus, significant role of these predatory beetles has been identified in regulating the population of many serious pests of crops, fruits and vegetables (Dhaka and Pareek, 2007). Considering the significant role of coccinellids, this study was conducted to determine the predatory potential of adult Coccinella septempunctata and Menochilus sexmaculata on eggs and nymphs of P. minor.

\section{Materials and Methods}

\section{Collection and rearing of Planococcus minor}

The collection of $P$. minor was carried out from the surroundings of National Agriculture Research Centre (NARC) research fields from Hibiscus rosachinensis. Both, adult females and immature stages of the mealybugs were collected, especially from the heavily infested China rose plants. The collected mealybugs were brought to the laboratory and transferred to pumpkin for further rearing. Fresh and thoroughly washed pumpkin fruits were used as the host for the multiplication of P. minor.

\section{Collection and rearing of Menochilus sexmaculata and Coccinella septempunctata}

Various stages of both coccinellid predators were also collected from the surroundings of NARC. After collections, they were brought to the laboratory and further reared on aphids and mealybug species.

The rearing of both $P$. minor and its coccinellid predators was done at $25 \pm 2{ }^{\circ} \mathrm{C}$ temperature and $60 \pm 5 \%$ relative humidity.

\section{Experiment setup}

China rose was selected as host plant in the experiment. One leaf was placed in the petri dish $(100 \times 15 \mathrm{~mm}$ size $)$, having a hole so that the petiole of the leaf can be passed through and dipped into the water kept in the plastic cup (100 $\mathrm{ml}$ capacity) to prevent the desiccation of leaf. Two treatments were used in the experiment i.e., $\mathrm{T} 1=P$. minor eggs and T2 $=P$. minor nymphs. Both eggs and nymphs $P$. minor were supplied to $M$. sexmaculata and $C$. septempunctata adults in no-choice basis in separate petri dishes. Fifty individuals (either eggs or nymphs) obtained from laboratory reared culture were transferred to China-rose leaf in the petri dish with the help of a camel hair brush. One adult of either species, starved for 24 hours was released in the individual petri dish. The observations were recorded on daily basis till the death of adults, whereas, fresh eggs and nymphs of $P$. minor were supplied to them on daily basis.

The collected data was analyzed using ANOVA with mean separation done by the Least Significant Difference (LSD) at 0.05 probability using STATISTIX 8.1 software.

\section{Results and Discussion}

Table 1 showed the detailed results regarding the feeding preference of adult $M$. sexmaculata and $C$. septempunctata on eggs and nymphs of $P$. minor. According to results, a highly significant difference was recorded for feeding preference of $M$. sexmaculata on different stages $(\mathrm{F}=75.32, \mathrm{P}=<0.001)$ of mealybugs on various observation days $(\mathrm{F}=28.29, \mathrm{P}<0.001)$. It has been observed that mean consumption increases initially, but gradually decreased after day four and six respectively. Thus, the highest consumption of $P$. 
minor eggs $(34.67 \pm 2.96)$ and nymphs $(42.67 \pm 2.91)$ by $M$. sexmaculata was recorded on day four and six, respectively. Mean feeding potential of $M$. sexmaculata for eggs and nymphs was observed $29.00 \pm 1.48$ and $21.18 \pm 1.54$, respectively. Menochilus sexmaculata showed comparatively more preference for $P$. minor eggs $(29.00 \pm 1.48)$ than nymphs $(21.18 \pm 1.54)$.

Table 1: Feeding potential of $M$. sexmaculata and $C$. septempunctata adults on eggs and nymphs of $P$. minor under laboratory conditions.

\begin{tabular}{lllll} 
Days & \multicolumn{2}{l}{ Species } & & \\
& \multicolumn{2}{l}{ M. sexmaculata } & \multicolumn{2}{l}{ C. septempunctata } \\
& P. minor & P. minor & P. minor & P. minor \\
& eggs & nymphs & eggs & nymphs \\
One & $26.00 \pm 3.21$ & $31.33 \pm 1.86$ & $27.67 \pm 3.18$ & $14.00 \pm 3.06$ \\
Two & $29.67 \pm 2.60$ & $33.67 \pm 2.85$ & $27.33 \pm 1.45$ & $16.33 \pm 2.85$ \\
Three & $31.67 \pm 2.85$ & $35.00 \pm 2.08$ & $29.33 \pm 2.96$ & $17.00 \pm 1.15$ \\
Four & $34.67 \pm 2.96$ & $36.33 \pm 2.03$ & $31.33 \pm 3.48$ & $18.67 \pm 1.20$ \\
Five & $34.00 \pm 2.65$ & $37.00 \pm 3.21$ & $33.33 \pm 2.03$ & $21.67 \pm 2.19$ \\
Six & $23.33 \pm 3.84$ & $42.67 \pm 2.91$ & $25.00 \pm 2.31$ & $18.67 \pm 1.45$ \\
Seven & $18.00 \pm 2.52$ & $33.00 \pm 1.15$ & $21.33 \pm 1.45$ & $16.00 \pm 1.00$ \\
Eight & $16.67 \pm 2.60$ & $31.00 \pm 2.08$ & $17.33 \pm 2.33$ & $13.00 \pm 1.15$ \\
Nine & $15.67 \pm 1.76$ & $27.00 \pm 1.15$ & $16.33 \pm 1.86$ & $12.33 \pm 1.45$ \\
Ten & $13.33 \pm 1.86$ & $22.00 \pm 2.08$ & $13.33 \pm 1.86$ & $9.00 \pm 0.58$ \\
Eleven & $12.00 \pm 1.53$ & $19.67 \pm 1.20$ & $9.00 \pm 1.15$ & $8.33 \pm 1.20$ \\
Twelve & $11.00 \pm 1.15$ & $15.33 \pm 1.45$ & $7.33 \pm 1.20$ & $7.33 \pm 1.45$ \\
Thirteen & $9.33 \pm 1.86$ & $13.00 \pm 1.00$ & $7.00 \pm 0.58$ & $6.33 \pm 1.45$ \\
Overall & $29.00 \pm 1.48 \mathrm{a}$ & $21.18 \pm 1.54 \mathrm{~b}$ & $20.44 \pm 1.54 \mathrm{~b}$ & $13.74 \pm 0.85 \mathrm{c}$ \\
mean & & & &
\end{tabular}

*Overall means followed by same letters are not significantly different (LSD, $P<0.05)$.

Similar to $M$. sexmaculata, a highly significant difference was recorded for the daily consumption ( $\mathrm{F}=26.20, \mathrm{P}<0.001)$ of $C$. septempunctata on eggs and nymphs $(\mathrm{F}=77.50, \mathrm{P}<0.001)$ of $P$ minor. However, comparatively slower rise in consumption of $P$. minor nymphs and eggs by $C$. septempunctata was recorded in comparison to $M$. sexmaculata. The highest daily consumption of $C$. septempunctata on eggs $(33.33 \pm 2.03)$ and nymphs $(21.67 \pm 2.19)$ of $P$. minor was recorded day five. Moreover, rate of daily consumption of the beetle on eggs and nymphs declined afterwards. Overall mean feeding of $C$. septempunctata on eggs and nymphs of $P$. minor stood at $20.44 \pm 1.54$ and $13.74 \pm 0.85$, respectively.

Results of the study confirmed relatively higher feeding potential $(\mathrm{F}=184.19, \mathrm{P}<0.001)$ of $M$. sexmaculata than $C$. septempunctata on both eggs and nymphs of $P$. minor.

Results of the study confirmed significant feeding potential of the both $M$. sexmaculata and $C$. septempunctata on the eggs and nymphs of $P$. minor. Many previous studies have also confirmed that coccinellid predators particularly Cryptolaemus montrouzieri on many species of mealybugs in various countries of the world (Mani, 1995; Mani and Krishnamoorthy, 2002; Persad and Khan, 2002; Ozgokce et al., 2006; Attia and El-Arnaouty, 2007). Besides, $C$. montrouzieri, various other coccinellids i.e., Brumoides suturalis, C. septempunctata, $M$. sexmaculata and others have also been identified to manage the populations of mealybugs (Chandrababu et al., 1997). A gradual increase in the daily consumption of both the species coccinellids was recorded on the eggs and nymphs of $P$. minor, but, it decreased after reaching at the highest feeding rate. It has been the general observation in previous research studies that feeding of adult predators including coccinellids showed an increasing trend and reach peak, corresponding the mating and oviposition of females. Moreover, significant effect of prey densities has also been identified on the feeding of coccinellids as comparatively higher consumption is observed in lower prey densities than higher densities, mainly because of searching, handling and consumption of prey is comparatively easy at lower densities (Agarwala et al., 2001; Omkar and Srivastava, 2003; Rana, 2006; Qin et al., 2014; Saleem et al., 2014).

\section{Conclusions and Recommendations}

Both species of coccinellid i.e., $M$. sexmaculata and C. septempunctata showed their feeding potential against eggs and nymphs of $P$. minor. Comparatively, $M$. sexmaculata showed higher feeding than $C$. septempunctata on various immature stages of $M$. minor. Moreover, both the species showed relatively more preference on eggs of $P$. minor than nymphs.

\section{Author's Contribution}

Muhammad Ishaque Mastoi: Conceived the idea and supervise the studies from data collection to report writing.

Arfan Ahmed Gilal: Statistical analysis and review and improvement of manuscript.

Anjum Shezad, Ahmed Zia and Abdul Rauf Bhatti: 
Taxonomic identification of pest and predators and critical review of manuscript.

Ibtasam Riaz: Data collection and report writing on predatory potential of Menochilus sexmaculata.

Syed Muneeb Rizvi: Data collection and report writing on predatory potential of Coccinella septempunclata.

\section{References}

Agarwala, B.K., P. Bardhanroy, H. Yasuda and T. Takizawa. 2001. Prey consumption and oviposition of the aphidophagous predator Menochilus sexmaculatus (Coleoptera: Coccinellidae) in relation to prey density and adult size. Environ. Entomol.30(6): 1182-1187. https://doi.org/10.1603/0046-225X-30.6.1182

Attia, A.R. and S.A. El-Arnaouty. 2007. Use of the coccinellid predator, Cryptolaemus montrouzieri Mulsant against the striped mealybug, Ferrisia virgata (Ckll.) on the ornamental plant, Agalypha macrophylla in Egypt. Egypt J. Biol. Cont. 17(1/2): 71-76.

Bastos, C.S., R.P. de Almeida, F. das, C. Vidal Neto and G.P. de Araújo. 2007. Ocorrência de Planococcus minor Maskell (Hemiptera: Pseudococcidae) em algodoeiro no Nordeste do Brasil. Neotropic. Entomol. 36(4): 625-628. https://doi.org/10.1590/S1519566X2007000400025

Ben-Dov, Y. 1994. A systematic catalogue of the mealybugs of the world (Insecta: Homoptera: Coccoidea: Pseudococcidae and Putoidae). Intercept Limited, Andover, United Kingdom.

Chandrababu, A., R.D. Gautam and A.K. Garg. 1997. Effect of temperature and relative humidity on the development of predatory beetle, Brumoides suturalis. Ann. Plant Prot. Sci. 5: $142-145$

CAB. 2003. Crop protection compendium: global module. Wallingford, UK.

Cox, J.M. 1989. The mealybug genus Planococcus (Homoptera: Pseudococcidae). Bull. British Museum (Nat. Hist.), Entomol. 58(1): 1-78.

Dhaka, S.R. and B.L. Pareek. 2007. Seasonal incidence of natural enemies of key insect pests of cotton and their relationship with weather parameters. J. Plant Prot. Res. 47(4): 418-419.

Francis, A.W., M.T. Kairo, A.L. Roda, O.E. Liburd and P. Polar. 2012. The passionvine mealybug, Planococcus minor (Maskell) (Hemiptera:
Pseudococcidae), and its natural enemies in the cocoa agroecosystem in Trinidad. Biol. Cont. 60(3): 290-296. https://doi.org/10.1016/j. biocontrol.2011.12.002

Ho, H.Y., C. Hung, T. Chuang and W. Wang W. 2007. Identification and synthesis of the sex pheromone of the passionvine mealybug, Planococcus minor (Maskell). J. Chem. Ecol. 33: 1986-1996. https://doi.org/10.1007/s10886007-9361-7

Irshad, M. 2001. Distribution, hosts, ecology and biotic potentials of coccinellids of Pakistan. Pak. J. Biol. Sci. 4(10): 1259-1263. https://doi.org/10.3923/pjbs.2001.1259.1263

Maity, D.K., A.K. Sahoo and S.K. Mandal. 1998. Evaluation of laboratory hosts for rearing and mass multiplication of Planococcus minor (Maskell) (Pseudococcidae: Hemiptera). Environ. Ecol. 16: 530-532.

Mani, M. 1995. Studies on the natural enemies of oriental mealybug, Planococcus lilacinus (Ckll.) (Homoptera: Pseudococcidae) in India. J. Entomol. Res. 19: 61-70.

Mani, M. and A. Krishnamoorthy. 2002. Biological suppression of spherical mealybug Nipaecoccus viridis (Newstead) (Hemiptera, Pseudoccidae) on acid lime in India. Entomon. 27: 423-424.

Martinez, M. and M. Suris. 1998. Biology of Planococcus minor Maskell (Homoptera: Pseudococcidae) under laboratory conditions / Biología de Planococcus minor Maskell (Homoptera: Pseudococcidae) en condiciones de laboratorio. Rev. de Prot. Vegetal. 13: 199201.

Mustafa, G., M. Saeed, A. Ali and M. Latif. 1996. Population dynamics of aphid and predatory coccinellid beetles of sorghum crop at Bahawalpur [Pakistan]. Proce. Second Int. Cong. Entomol. Sci. Islamabad (Pakistan), 1921 Mar 1996. PARC.

Omkar and S. Srivastava. 2003. Influence of prey species on certain biological attributes of a ladybird beetle, Coccinella septempunctata. Biocontrol. 48: 379-393. https://doi. org/10.1023/A:1024762822955

Ozgokce, M.S., R. Atlihan and I. Karac. 2006. The life table of Cryptolaemus montrouzieri Mulsant (Coleoptera: Coccinellidae) after different storage periods. J. Food Agric. Environ. 4: 282287.

Persad, A. and A. Khan. 2002. Comparison of life 
table parameters for Maconellicoccus birsutus, Anagyrus kamali, Cryptolaemus montrouzieri and Scymnus coccivora. Bio. Cont. 47: 137-149.

Qin, Z.Q., B.L. Qiu, J.H. Wu, A.G. Cuthbertson and S.X. Ren. 2014. Effects of three mealybug species on the development, survivorship and reproduction of the predatory lady beetle Cryptolaemus montrouzieri Mulsant. Biocont. Sci. Technol. 24(8): 891-900. https://doi.org/1 0.1080/09583157.2014.903225

Rana, J.S. 2006. Response of Coccinella septempunctata and Menochilus sexmaculatus (Coleoptera: Coccinellidae) to their aphid prey, Lipaphis erysimi (Hemiptera: Aphididae) in rapeseed-mustard. Eur. J. Entomol. 103(1): 81. https://doi.org/10.14411/eje.2006.013

Reddy, K.B., P.K. Bhat and R. Naidu. 1997. Suppression of mealybugs and green scale infesting coffee with natural enemies in
Karnataka. Pest Manage. Econ. Zool. 5: 119121.

Saleem, M., D. Hussain, H. Anwar, M. Saleem, G. Ghouse and M.Abbas.2014.Predation Efficacy of Menochilus sexmaculatus Fabricus (Coleoptera: Coccinellidae) against Macrosiphum rosae under laboratory conditions. J. Entomol. Zool. Stud. 2(3): 160-163.

Tandon, P.L. and A. Verghese A. 1987. New insect pests of certain fruit crops. Ind. J. Hort. 44: 121-122.

Venette, R.C. and E.E. Davis. 2004. Mini risk assessment, passionvine mealybug: Planococcus minor (Maskell) (Pseudococcidae: Hemiptera). National Cooperative Agricultural Pest Survey (CAPS) Target Pests CAPS PRA: Planococcus minor.

Williams, D.J. and M.C. Granara deWillink. 1992. Mealy-bugs of central and south America. CAB Int., Wallingford, U. K. 